\title{
Estrategias literarias en las reescrituras contemporáneas de los cuentos tradicionales
}

\author{
Literary strategies in contemporary versions of fairy tales
}

\author{
Fabiola Mancilla Pinda, Susana Bahamonde, Andrea Pac \\ fabii_mancilla@hotmail.com,sbahamonde@uarg.unpa.edu.ar,apac@uarg.unpa.edu.ar \\ Unidad Académica Río Gallegos- Universidad Nacional de la Patagonia Austral \\ Piloto Rivera s/n - Río Gallegos - Santa Cruz - Argentina
}

Recibido: 10/10/2021. Aceptado: 16/12/2021

\begin{abstract}
RESUMEN
Los cuentos tradicionales son relatos que han perdurado a lo largo del tiempo. Transmitidos de forma oral y anónima en un principio, fueron la herramienta cultural que permitió que adultos y niños de distintas sociedades conocieran el mundo y sus valores. A lo largo del siglo $\mathrm{XX}$ y hasta nuestros días, los relatos tradicionales han sido reescritos y reversionados en múltiples géneros y soportes. Las reescrituras en nuevos textos de literatura infantil son particularmente ricas por su carácter intertextual y por la pluralidad de estrategias literarias que despliegan: modificación o intercambio de roles de los personajes, incorporación de perspectivas sociales actuales, alteraciones en la secuencia del relato. Estas reescrituras son a un tiempo agentes de la transmisión cultural y productoras de cultura contemporánea; acercan a los más nuevos el mundo que les preexiste, y abre ese mundo a la novedad.

Este informe se propone caracterizar teóricamente las reescrituras de los cuentos tradicionales y describir las estrategias más habituales mediante las cuales estos textos producen una literatura nueva. Para lo primero, recorrerá los conceptos de cuentos tradicionales o folclóricos, también conocidos como cuentos de hadas, así como las nociones de traducción, intertextualidad, resemantización y reescritura. Para lo segundo, analizará un corpus de textos de literatura infantil, seleccionado según la frecuencia de las reversiones existentes. Se argumentará así el valor cultural y literario de estos textos, más allá de las intenciones didácticas o moralizantes.
\end{abstract}

Palabras clave: Reescritura; Transmisión; Literatura infantil; Cultura.

\begin{abstract}
Fairy tales are stories that have lived on in our culture. In the beginning, they used to be anonymous, and passed on orally, and they offered adults and children knowledge of their world and social values. Along the 20th Century and into our times, the traditional stories have been rewritten and reversioned in multiple genres and formats. The children's literature versions are especially interesting due to the intertextuality and the variety of literary strategies they display: roles are exchanged or transformed, present social perspectives are introduced into old stories, the sequence of the tale is altered. These new versions both transmit the cultural heritage and produce a new contemporary culture; they offer the new ones a world that exists before they come into it, and they open the world to renovation.

This paper aims to describe a theoretical framework for the contemporary versions of fairy tales, and describe the most usual strategies by means of which these texts produce a new kind
\end{abstract}


of literature. It reviews the notions of traditional, folk or fairy tales, as well as the concepts of translation, intertextuality, resemantization and rewriting. Then, it will analyse a body of children's literature books, chosen according to how frequently they have been reversioned. It will argue in favour of these book's cultural and literary value, beyond didactic or moral intentions.

Keywords: Rewriting; Transmission; Children's literature; Culture.

\section{INTRODUCCIÓN}

Los cuentos tradicionales o clásicos, también llamados cuentos de hadas, son relatos que tienen su origen en el folclore de cada sociedad cuya transmisión, en una primera instancia, fue de forma oral. Fueron testigos de distintos momentos históricos y por ello, están cargados de cultura humana (Salmerón Vílchez, 2005). A partir del siglo XIX, gracias a los Hermanos Grimm, Charles Perrault o Christian Andersen (por nombrar a los compiladores más conocidos) pasaron a ser escritos, en algunos casos menos crueles que los 'originales' (Alcubierre Moya, 2015), con el fin de ofrecer a los niños representaciones de modelos culturales. En el presente, estas narraciones se continúan transmitiendo y adaptando a los contextos actuales pero sin perder los argumentos o personajes centrales. Así, se reconoce en las producciones literarias de las últimas décadas a personajes tales como Caperucita Roja, Cenicienta, los tres chanchitos, entre otros.

Las diversas adaptaciones son una práctica frecuente que facilita que los relatos clásicos perduren en el tiempo y tengan un mayor protagonismo en la literatura infantil (Matas García, 2016). Los textos se actualizan pero también permiten una relación intertextual no sólo en lo que refiere a aspectos literarios sino también de valores y modelos culturales. La intertextualidad, de acuerdo a lo que sostiene Genette, es "una relación de copresencia entre dos o más textos" (1989, p. 10); en este caso, entre el texto tradicional y la nueva escritura. Acerca de esta relación de copresencia, la intertextualidad adquiere distintas formas y en las versiones actualizadas constituyen una de las estrategias fundamentales de reescritura.

Existen múltiples versiones de los cuentos tradicionales que atraviesan los géneros y los soportes, tales como narraciones y animaciones en YouTube, versiones cinematográficas, teatrales, musicales. Este trabajo se concentrará en los textos literarios. Su objetivo es ofrecer un panorama de las reescrituras de los cuentos tradicionales de las últimas décadas y desarrollar un análisis de las estrategias de reformulación de las historias. La hipótesis que guía esta investigación consiste en que son valiosas desde el punto de vista literario y aportan elementos estéticos y de sentido que contribuyen a la transmisión y renovación cultural. Con esta investigación esperamos realizar un aporte al desarrollo del área de investigación de la Literatura Infantil en la UNPA.

Con este fin, se desarrollará en primer lugar una síntesis del estado actual de las investigaciones en el campo. En segundo lugar, se expondrá la noción de cuento tradicional y su incorporación en el género de la literatura infantil. En tercer lugar, se explorarán los conceptos de intertextualidad, traducción, resemantización y reescritura -todos ellos utilizados para encuadrar las nuevas versiones de los textos- y se justificará por qué preferimos el último de ellos para nuestro trabajo. Por último, se analizará un corpus literario de reescrituras de Caperucita Roja, Los tres cerditos, Cenicienta, Blancanieves, La Bella Durmiente y Hansel y Gretel. Éste permitirá identificar las estrategias literarias que enriquecen a estos relatos, así como el diálogo cultural que establecen con la tradición. 


\section{MARCO DE REFERENCIA}

\section{Cuentos tradicionales y literatura infantil}

¿Cuál es el origen de los cuentos tradicionales? ¿Cómo llegan a nosotros? ¿Cuál ha sido su función cultural y literaria con el transcurso del tiempo? Los cuentos tradicionales son narraciones que han sufrido diversas transformaciones hasta llegar a los lectores actuales. En principio, su origen se remonta mucho antes de la existencia de la vía culta de circulación de los textos, es decir, ubicamos el punto de partida en las narraciones populares, en una cultura en la que predominaba la oralidad. En palabras de Carranza,

no son otra cosa que versiones de relatos cuyo origen se pierde en la historia de la humanidad, y en definitiva no son sino adaptaciones realizadas por individuos pertenecientes a las clases intelectuales que han decidido llevar tales relatos de la tradición oral a la escritura. (2012, s/p)

Otra manera de denominar estos relatos es como cuentos folclóricos. Según Rowe, el folklore es

un mecanismo importante para mantener la estabilidad de la cultura. Se usa para inculcar a los niños las costumbres y estándares éticos, y para recompensar con orgullo a los adultos cuando se adecuan y castigarlos con el ridículo cuando se desvían, para proveerlos con racionalizaciones cuando las instituciones y convenciones son desafiadas o cuestionadas, para sugerir que puede conformarse con las cosas como son ofrecerles un escape compensatorio de las dificultades, las desigualdades y las injusticias de la vida cotidiana. (Bascom, 1954 en Rowe, 1986, nota 5 , p. 223, nuestra traducción)

Desde este punto de vista, los relatos tradicionales tenían una función edificante pero también lúdica. A diferencia del presente, en el que han quedado enmarcados en la categoría de literatura infantil, su público era amplio y diverso, y sus temas no estaban segmentados según el destinatario. A este respecto, Zipes observa que no tenían una denominación en particular y que "se contaban simplemente para marcar un acontecimiento, dar un ejemplo, advertir sobre un peligro, obtener alimentos o explicar lo que era inexplicable. La gente relataba historias para comunicar conocimiento y experiencia en contextos sociales" $(2014$, p. 23).

Cerrillo (2016) plantea que no es algo disparatado pensar el contexto en el que las antiguas sociedades transmitían de generación en generación estos cuentos populares: junto al fuego, rodeado de niños y adultos, se contaban diversas aventuras, episodios reales e inventados, que habían oído contar a alguien o que eran fruto de su imaginación. Esta imagen de una narración típica da cuenta tanto de las variaciones como del carácter universal que subyace a las distintas versiones en las que circulaban estas historias: como se trataba de un material colectivo, una obra abierta, de origen anónimo, cada narrador le daba un rasgo propio de acuerdo a su cultura, a la región en la que viviera. Así, la estructura de la historia o los personajes principales permanecen, pero se incorporan cualidades propias de las zonas en que se transmiten las historias y se alteran los detalles según las costumbres de cada región. Por ello, los cuentos populares forman parte del patrimonio colectivo y recogen creencias, costumbres y valores de una cultura determinada. Estas narraciones constituyen "el eslabón perdido de una cadena que, por un lado nos conduce a los conflictos fundamentales de la sociedad, a lo largo de toda su historia, y, por otro, a los conflictos internos de la personalidad" (Rodríguez Almodóvar, 1998, p. 40).

Todos estos relatos contenían un valor iniciático (Eliade, 1968) y los sujetos podían sentirse identificados con los personajes, de algún modo la realidad se veía reflejada en las historias. En muchos casos, los relatos adquirían un tono moralizante y aleccionador, puesto que al insertar a los sujetos en el mundo, debían evidenciar a través de las historias lo bueno y lo malo, los peligros y la bondad, cuestiones propias de la vida. El surgimiento de los estudios 
de la infancia y la consideración (o construcción) del niño como tal a fines del siglo XVIII, convergerá con los procesos de transcripción de los cuentos tradicionales orales. Con ellos, las historias se despojan de rasgos sexuales, irónicos o violentos para la representación ideal de la infancia (Carranza, 2012; Alcubierre Moya, 2005). Historias como las de Cenicienta, Caperucita Roja, La bella durmiente, en las que se encontraba un contenido fuerte en cuanto a violaciones, maltratos o escenas escatológicas, se ven adaptadas a los nuevos receptores.

Los recopiladores han sido piezas fundamentales para preservar la tradición pues se encargaron de escribir todas las historias que circulaban en sus respectivas sociedades. Todos vieron la importancia de preservar la cultura ya que estos relatos estaban destinados a desaparecer. Los más conocidos fueron Charles Perrault y los hermanos Grimm. El caso de Christian Andersen, muy citado también en los estudios que corresponden a los cuentos tradicionales, merece un estudio aparte ya que sus escritos son propios, basados en las historias populares de su lugar de origen. Si bien cada uno de los recopiladores pertenece a diferentes lugares de Europa, y por ende cada escritura tiene sus particularidades, todos asumen la tarea de escribir para niños con el fin de educarlos, continuar con el legado cultural pero a la vez no pierden de vista el mundo de fantasía e imaginación. Según López Tamés, Perrault, pero sobre todo, los hermanos Grimm, dulcificaban "el desmesurado mundo que nutre lo popular" (1990, p.139) ya que se encargaron de modificar los finales trágicos o macabros por finales felices, algunos valores acerca del bien y el mal, la justicia y de reflejar el valor de luchar por la vida pese a los obstáculos (Vílchez, 2005). Es así como los cuentos tradicionales devienen literarios (Feijoo, 1984) y, en el siglo XX, su incorporación al mercado editorial con un destinatario infantil contribuye a su definición como un género literario específico de literatura infantil o cuentos de hadas.

Con esta categorización, surgen las críticas (Colasanti, 2004) y también los estudios acerca de la función de los cuentos de hadas en la formación de la personalidad de los niños. Así se desprenden análisis como el de Bruno Bettelheim (1975) sobre los cuentos de hadas, quien sostiene que estos relatos representan la esencia del proceso de desarrollo humano y que contribuyen psicológicamente de forma positiva en el crecimiento interno de los niños. Ahora bien, este psicoanalista plantea algo muy interesante para el estudio del presente trabajo: los aportes que propician el desarrollo de los niños están ligados a la condición de arte de estas historias, es decir a su calidad literaria.

En todos los cuentos tradicionales, las estructuras de las narraciones así como ciertos personajes estereotipados, son una constante. La estructura y los temas han sido objeto de numerosos estudios e inventarios. Entre los más conocidos, Propp publica en 1928 su ya clásica Morfología del cuento, en la que se propone estudiar la estructura de los cuentos para establecer una base científica de su estudio: "Evidentemente, antes de dilucidar la cuestión del origen del cuento, hay que saber qué es el cuento" (2009, p. 12), afirma para fundamentar su postura. Por su parte, en 1910, desde la Escuela Finlandesa, Aarne propuso un sistema numérico-alfabético de clasificación de los cuentos populares en 540 tipos, que Thompson revisó y completó en 1928 (The Types of the Folk-Tale) hasta que se publicó la versión final en 1961, a su vez revisada por Uther en 2004 (Zipes, 2014; Hernández Fernández, 2006) ${ }^{1}$.

En la actualidad, los estudios académicos sobre literatura infantil en lengua inglesa suelen preferir la expresión fairy tales para referirse a los textos que aquí denominamos cuentos tradicionales. Según Zipes (2014) fue usado por primera vez por madame D’Aulnoy en una antología en 1697, y fue adoptado de ahí en más para titular obras en los siglos siguientes. La denominación de cuentos de hadas o cuentos maravillosos también es aceptada en el mundo

\footnotetext{
${ }^{1}$ Es posible ver la codificación de Aarne-Thompson en https://sites.ualberta.ca/ urban/Projects/English/Content/ATU_Tales.htm
} 
de habla hispana. Estas denominaciones se suelen usar de manera intercambiable. Pero más allá de las etiquetas, es importante tener en cuenta que

la intrincada relación entre los cuentos de hadas y los folclóricos y su compleja evolución son difíciles de captar y definir. De hecho, los cuentos orales y los literarios conforman conjuntamente un género inmenso y complejo porque existe entre ellos una dependencia insoluble. (Zipes, 2014, p. 24)

Esta advertencia indica que aun la distinción versión oral/versión escrita puede ser una falsa dicotomía (Zipes, 2014, p. 25), y que en los trabajos de investigación es más importante tomar una decisión operacional antes que intentar determinar una definición estricta. En este trabajo se preferirá la denominación de tradicional dado que el foco de nuestro interés está puesto en sus reescrituras y no en sus elementos fantásticos, y partiremos de la tradición escrita de estos cuentos.

\section{La permanencia de los cuentos tradicionales}

Cabe subrayar que, como se señaló más arriba, los cuentos tradicionales ya son una reescritura de los relatos orales populares. Los procesos de recopilación y registro de los relatos orales implicaron también una adaptación a los contextos, al lenguaje escrito, a la representación del destinatario lector y a las motivaciones e intereses de quienes llevaron a cabo esa tarea. En efecto, las versiones de Perrault, Grimm y Andersen de una misma historia difieren entre sí no sólo en detalles, sino en aspectos relevantes. Cuando aquí se revisan las reescrituras contemporáneas, no se está pensando en el tipo de diferencias entre estas versiones. El objeto de este análisis serán principalmente las técnicas de reescritura y no, por ejemplo, si un leñador o un cazador rescata finalmente a Caperucita y a su abuela o no (en Perrault no lo hay, mientras que en Grimm sí), o qué edad tenía Blancanieves cuando su madrastra ordena su muerte (17 según Perrault, 7 según Grimm), o si las de Cenicienta son hermanas (Grimm) o hermanastras (Perrault) y si son castigadas o no al final de la historia, o si sus deseos son concedidos por un árbol (Grimm) o un hada madrina (Perrault). Tampoco tomaremos como texto de partida de las reescrituras a una de estas versiones en particular, dado que la referencia de las reescrituras a su versión tradicional es un diálogo más amplio que este tipo de detalles, y no es necesario conocer una versión en particular para entrar en él. Zipes (2014) subraya un valor intrínseco de los cuentos tradicionales. Argumenta que, a pesar de que "se ha vuelto imposible para los artistas serios aceptar las tradicionales estructuras y 'bondad' de los cuentos de hadas en un mundo globalizado que está fuera de control", esa "moralidad ingenua todavía puede encontrar eco en nosotros" y, por eso, "las obras de arte contemporáneas referidas a cuentos de hadas, aunque a menudo distópicas, siguen latiendo con fervor utópico" (p. 264). Por dar un ejemplo, en el caso de Caperucita Roja, en la versión de Perrault el cuento habla sobre la seducción, parece tener la intención de instruir a las niñas sobre las reglas sociales para el control de la sexualidad. En la versión posterior de los hermanos Grimm de 1819, el cuento se desplaza hacia un mensaje formativo en relación a la obediencia que se debe a las madres y se introduce el final feliz. En ambos casos aparece el didactismo moral, encarnado en elementos como la advertencia de una madre a su hija, la presentación del bosque como un escenario masculino y riesgoso (donde habitan el lobo y el cazador), la decisión de correr el riesgo o incluso el interés por hacerlo por parte de la niña, una devoración y una restitución del orden, ambas acciones a manos de personajes masculinos.

Estos elementos señalan un conjunto de tópicos que se han tornado fácilmente rebatibles a la luz de las preocupaciones sociales que desde finales del siglo XX en adelante se han orientado hacia la igualdad de género, el respeto a la diversidad, la consideración del niño como objeto de derecho, la mirada agudizada sobre la realidad social y las relaciones humanas potenciada por el desarrollo de múltiples enfoques que se ocupan de abordarlas. Así, el modelo cultural 
contenido originalmente el texto, centrado en la transmisión del temor a la pérdida de la honra o a las consecuencias de la desobediencia, entra en contradicción cabal con los modelos culturales vigentes. Ese contraste que deja la sensación de abismo entre modelos culturales del pasado y del presente nos lleva a la no indiferencia ante este texto. El contraste operaría como motor que vehiculiza las reescrituras como recurrentes intentos de que ese texto se lea a la luz de nuevas perspectivas.

Esta perspectiva, que es compartida por escritoras/es y críticas/os como Andruetto (2021), Colasanti (2004), Martín Garzo (2012), no es sin embargo, ni lo principal, ni lo que llama la atención en las obras que se analizan en nuestra investigación. Las reescrituras contemporáneas de estos relatos son, en el fondo, juegos literarios. En algunos casos, como por ejemplo en las reescrituras feministas (Casado Presa, 2017), pueden apoyarse en ese contenido moral para desestabilizar tanto la identidad formal y cultural de los cuentos, subvertir las relaciones actuales de poder del presente y sentar una posición política. Pero aquí no se incluirán textos de clara intención didáctica o aleccionadora. En cambio, se pondrá énfasis en una producción que, si bien no se desentiende de las tensiones entre modelos culturales del pasado y del presente, invita al lector a dejarse entretejer en el entramado de la cultura que lo conecta a las referencias del pasado y a la vez lo proyecta hacia un mundo literario nutrido de posibilidades de entrecruzamientos, desvíos y continuidades.

\section{El concepto de reescritura}

Muchas son las formas de conceptualizar los cuentos actuales que retoman y modifican en algún punto los cuentos tradicionales y clásicos y las técnicas de escritura de estas obras. Matas García (2017) las reduce a traducción (lingüística), adaptación (contextual) y versión (no atada al contexto). Otras nociones que circulan en el mismo sentido son reversión, recontextualización, revisitación, parodia, intertextualidad. La referencia a estos conceptos y técnicas es en general diversa e inestable. Versión y adaptación resultan similares, en cuanto se plantean habitualmente como reformulaciones medianamente fieles a los relatos conocidos a través de los recopiladores. Aunque el término adaptación se percibe también como forma específicamente ajustada para un destinatario, fin o medio particular (Sotomayor Sáez, 2005). Parodia suele usarse para designar una nueva forma de contar la historia que ironiza sobre algunos de sus aspectos. La recontextualización alude al cambio de contexto temporal o espacial que hace que la obra se modifique. Reversión y revisitación también parecen equivalentes, en cuanto designan una historia que se vuelve a contar desde otra perspectiva. Intertextualidad es más amplio, desde sus primeras definiciones planteadas por Kristeva y Genette todo lo descrito hasta aquí entra dentro del fenómeno intertextual, entendido como relaciones y posibilidades de interacción, es decir, de diálogo, entre distintos enunciados literarios, interacción que trasciende los aspectos meramente formales del texto y se extiende a cuestiones culturales más vastas (Durañona et al., 2006, pp. 55-56).

En lo que sigue, nos detendremos en los conceptos de intertextualidad, traducción, resemantización y reescritura, con la intención de sistematizar la pluralidad de usos y subrayar los rasgos de cada uno que servirán a nuestro análisis de obras, tanto en la reconstrucción narrativa como en la identificación de las estrategias de reescritura.

\section{Intertextualidad}

Wilkie (2002) define tres niveles de intertextualidad según tres categorías de textos: los textos de citación (quotation), que "citan o aluden a otros trabajos literarios o no literarios"; los textos de imitación, que "parafrasean, 'traducen' y suplantan al original" tal como las versiones abreviadas de obras clásicas; los textos de género, que asumen códigos identificables del género (policial, de terror, romántico) y crean obras nuevas en las que los lectores esperan reconocer dichos códigos (p. 132, nuestra traducción). De acuerdo con esta 
categorización, las reescrituras objeto de este trabajo estarían en el orden de la citación. Según Wilkie, estos textos "desestabilizan de manera inteligente la seguridad de sus lectores" porque los posicionan en un lugar ambivalente con respecto a lo que creen que saben sobre los cuentos tradicionales y sobre la historia que están leyendo, y desafían la autoridad del narrador del texto 'original' (p. 132).

Desde luego, en el caso de los cuentos tradicionales, el supuesto texto original no es tal desde el momento en que ellos mismos son "un collage de citas (...) parte del discurso de la memoria popular sedimentada" (Wilkie, 2002, p. 132, nuestra traducción). Más aún, en el presente, la versión de estos relatos con la que los niños tienen un primer contacto suele ser la versión fílmica de las grandes compañías que lideran la industria cultural cinematográfica dirigida a los niños. Según Wilkie, el resultado es una experiencia intertextual peculiar dado que la primera versión conocida está ya adaptada a valores y rasgos de la cultura popular contemporánea.

La intertextualidad es, pues, un rasgo relevante en las reescrituras. Cuanto más versiones conozca previamente el lector, más desestabilizante y, por tanto, productiva en términos de producción de sentidos será la lectura. Por supuesto, esto depende de que las propuestas de las reescrituras tengan la riqueza necesaria para una intertextualidad reflexiva y que no sean meramente una capa actualizada para los mismos contenidos o valores (como suele ser el caso de las versiones cinematográficas popularizadas).

\section{Traducción}

A partir de la década de 1990, el giro traduccional (translational turn, Arduini y Nergaard, 2011; Bassnett, 2007; Bassnett y Trivedi, 1990) que tuvo lugar en las humanidades como desarrollo del giro cultural (cultural turn) en los estudios de traducción de la década anterior, permite pensar las reversiones de los cuentos tradicionales también en términos de traducciones culturales. Desde la perspectiva de los estudios de post-traducción (posttranslation studies), la reescritura de estos relatos es una traducción que no se limita al pasaje de una lengua a otra (como, de hecho, han llegado a los hispanohablantes los cuentos tradicionales). Esta noción alcanza a la transferencia del lenguaje escrito al lenguaje cinematográfico o teatral y la transformación de los sentidos culturales propios del contexto de los cuentos tradicionales a los sentidos culturales del presente. Asimismo, la relevancia de las ilustraciones en el libro álbum implica una doble traducción en un nuevo texto y en imágenes indispensables al relato, al punto que es posible identificar en las imágenes los mismos "recursos retóricos, figuras del habla y tropos (la metáfora visual, la hipérbole, la sinécdoque, la metonimia, etcétera) tanto en la comunicación verbal como en la imagen" (Di Paola, 2018, p. 4).

El reconocimiento de la raíz lotmaniana de los estudios de post-traducción la convierte no ya en la transferencia de significado entre dos lenguas diferentes, sino en los acontecimientos semánticos que tienen lugar en la zona de encuentro entre semiosferas. En consecuencia, la traducción es un proceso de transformación que alcanza a las culturas y los individuos (Arduini y Nergaard, 2011), un "paradigma para problemas más amplios de comprensión e interpretación a través de tradiciones discursivas diferentes" (Bernheimer, 1995, p. 44 en Hermans, 2007, p. 80, nuestra traducción). No es sólo la estructura lingüística de un texto lo que se traduce, sino el horizonte de sentidos de una cultura a otra o de una cultura en un momento de su historia a otro momento de su historia. Así, tanto la reescritura de los relatos como su reversión cinematográfica son casos de la traducción cultural.

Bassnet y Lefevere afirman que la traducción es una reescritura, pero habilitan una bidireccionalidad entre reescritura y traducción que las vuelve equivalentes:

Todas las reescrituras, cualquiera sea su intención, reflejan una cierta ideología y una poética y, como tales, manipulan la literatura para que funcione en una sociedad dada 
de una manera determinada. La reescritura es manipulación, asumida en el servicio del poder, y en su aspecto positivo puede ayudar en la evolución de una literatura y una sociedad. Reescribir puede introducir nuevos conceptos, nuevos géneros, nuevos artefactos y la historia de la traducción es la historia de la innovación literaria, del poder formativo de una cultura sobre otra. Pero la reescritura puede también reprimir la innovación, distorsionar y contener, y en una época de formas de manipulación creciente, el estudio de los procesos de manipulación de la literatura ejemplificados en la traducción pueden ayudarnos a enriquecer la comprensión del mundo en que vivimos. (2004 como se citó en Shuping, 2013, p. 56, nuestra traducción).

Esta reflexión sobre la traducción/reescritura advierte sobre aspectos a tener en cuenta en el análisis de los textos que nos interesan. En primer lugar, entendemos la manipulación de la que habla Lefevere sin suponer que exista una intención de sometimiento en quien manipula el texto. En segundo lugar, no necesariamente la reescritura de los cuentos tradicionales tiene por meta que sus contenidos y valores funcionen en el presente. Hemos sugerido más arriba que algunas adaptaciones cinematográficas sí contribuyen a que las historias se mantengan en un mundo en el que se produce un desplazamiento de la letra leída a la imagen; en especial, si pensamos en los valores, la representación de los roles de género, en síntesis, la ideología en general contenida en ellas. Por ejemplo, las princesas pueden renegar del rol tradicionalmente atribuido a las mujeres, pero siguen siendo princesas. Hay ahí una ideología muy clara que se mantiene y que se hace funcionar bajo el disfraz de la rebeldía con respecto a la ideología y las relaciones de poder tradicionales.

En cambio, hay reescrituras que transforman las relaciones de poder. Algunas de ellas lo hacen con una intención explícita de contribuir a la consolidación de una ideología específica. Tal es el caso de algunas versiones feministas de los cuentos tradicionales, como $\mathrm{La}$ cenicienta que no quería comer perdices de Nunila López Salamero. Sin embargo, otras reescrituras logran transformar las relaciones de poder priorizando una estética novedosa por sobre la moraleja. Estas reescrituras, entendidas como condensaciones de la semiosfera (Semenenko, 2012), dan cuenta de la pluralidad dinámica de la cultura. Penas-Ibáñez (2017) describe la cultura mediante una serie de analogías: la cultura es siempre intercultural según Lotman, así como el texto es siempre intertextual según Bakhtin, y la subjetividad es siempre intersubjetiva en la hermenéutica. Y concluye:

sólo siguiendo estas líneas pueden las comunidades y sus miembros comunicarse entre ellos, y con otros en formas siempre cambiantes que afectan la transferencia cultural e intercultural. Uno de los efectos sobresalientes de esta transferencia es la hibridación de las formas genéricas textuales. (p. 153)

Las reescrituras de los cuentos tradicionales son una forma de transferencia cultural. Pero la manera en que producen nuevos sentidos las ubica en una frontera interna de la cultura (Lotman, 2019 [1999]) en la que el texto es propio tanto como extraño: propio, por ser una manera de apropiarse de la tradición; extraño porque la apropiación produce textos nuevos.

\section{Resemantización}

La resemantización forma parte del continuo proceso de simbolización que atraviesan todas las sociedades y que toma forma a través de diferentes medios: escritos, visuales, audiovisuales. Entendemos por resemantizar,

transformar el sentido de una realidad conocida o aceptada para renovarla o para hacer una transposición de modelo, creando una entidad distinta, pero con alguna conexión referencial con aquélla, de modo que esta última asume un nuevo significado que la primera no tenía. (Zeccheto, 2011, p. 127)

Relatos, eventos, personajes han sido consignados simbólicamente en siglos pasados y han pasado a formar parte de los imaginarios sociales y colectivos, quedando fijados en el tiempo 
y constituyéndose como clásicos referenciales o paradigmáticos para gran parte de la sociedad, tal es el caso de la niña con la caperuza roja, el lobo, el espejo mágico o el hechizo que hizo dormir a una princesa por años. Estos elementos registrados y asumidos socialmente son configurados a través de un lenguaje particular que permite leer en ellos otras significaciones.

Zeccheto plantea una tendencia humana a retomar sentidos anteriores haciendo recomposiciones:

Observemos, entonces, cómo en las expresiones creativas y en las formas prácticamente ilimitadas del lenguaje, el concepto de contemporáneo no pasa por su pertenencia a nuestra época, sino por el hecho de que una idea, un sentimiento o aspiración no termina de realizarse enteramente y siempre habrá alguien que la haga presente en forma resemantizada. (2011, p. 142)

Las reescrituras de los cuentos tradicionales pueden ser pensadas también como resemantizaciones que, tanto a través del medio escrito como del visual, se configuran como una sucesión de transformaciones, asociadas a la analogía, la metáfora y la polisemia.

\section{Reescritura}

Consideramos también la reescritura como parte de un continuum como el que propone Hutcheon, "ningún texto es una cosa fija: siempre hay una variedad de versiones manuscritas, revisiones, y diferentes ediciones impresas" (2006, p. 170). Todas ellas constituyen un "un continuum de relaciones fluidas entre los trabajos previos y sus revisitaciones posteriores $-\mathrm{y}$ simultáneas" (p. 171, nuestra traducción). Se trata de un continuum que va desde lo más cercano a lo más lejano en cuanto a su fidelidad con el texto previo. Dentro de este continuum la adaptación ocupa el lugar de la reinterpretación y de la recreación. En este sentido, la reescritura es también una adaptación:

No es una copia en algún modo de reproducción, mecánica o de otro tipo. Es repetición pero sin replicación, que vincula el consuelo del ritual y del reconocimiento con el placer de la sorpresa y la novedad. Como adaptación, incluye tanto el recuerdo como el cambio, la persistencia y la variación (Hutcheon 2006, p. 173, nuestra traducción).

No podemos dejar de pensar además el carácter de adaptación de las reescrituras que aquí nos ocupan, en las que las significaciones están entrañadas no solo por el texto sino también por el medio visual: la imagen y los detalles de edición son insoslayables.

De todas las conceptualizaciones, en este trabajo se prefiere la de reescritura. Desde nuestra perspectiva, ésta puede pensarse más allá del sentido de reformulación textual, como un concepto que puede nutrirse de elementos de la traducción, la resemantización, la intertextualidad y la adaptación y de esta forma reconfigurarse como una operación de traducción cultural amplia, que abarca una zona de confluencia entre operaciones semióticas e intertextuales e implica una transformación de una realidad conocida para renovarla o crear una entidad distinta. Así entendido y reconfigurado, el término reescritura resulta propicio a los fines de este trabajo, que se centra en las estrategias literarias de transformación de los relatos y en la productividad de sentido que promueven.

\section{CORPUS, ANÁLISIS Y DISCUSIÓN}

\section{Corpus}

El corpus para análisis se seleccionó en función de los cuentos tradicionales cuyas reescrituras son más comunes. De acuerdo con Baker-Sperry y Grauerholz (2003) los cuentos tradicionales más reversionados (ya sea en textos literarios, versiones dramáticas o 
cinematográficas) son cinco: Cenicienta, Blancanieves, La Bella Durmiente, Caperucita Roja y Hansel y Gretel (p. 720). En este trabajo se ha adoptado esta lista de relatos y se ha sumado Los tres chanchitos por haber encontrado un número bastante significativo de reescrituras disponibles en nuestro medio (es posible que no se incluyera en la lista de Baker-Sperry y Grauerholz por dos motivos principales: en primer lugar, porque su artículo se propone un rastreo de menciones a la belleza femenina, que no es un aspecto central de este cuento; en segundo lugar, no es uno de los textos más popularizados en versiones cinematográficas).

Para el análisis, se han reunido 27 reescrituras con la siguiente distribución: 10 de Caperucita Roja; 6 de Los tres Cerditos; 3 de Cenicienta; 4 de Blancanieves; 2 de La Bella Durmiente; 2 de Hansel y Gretel (Tabla 1). El estudio que se ha tomado como referencia, la historia más reversionada es la de Cenicienta (Baker-Sperry y Grauerholz, 2003); pero no se limita a obras de literatura infantil. La mayor cantidad de reescrituras literarias disponibles en nuestro medio es de Caperucita.

Tabla 1: Datos y abreviaturas del corpus

\begin{tabular}{|c|c|c|c|c|c|}
\hline Título & Autor/a & Ilustrador/a & $\begin{array}{l}\text { Idioma } \\
\text { original }\end{array}$ & Edición consultada & $\begin{array}{c}\text { Abreviatura con } \\
\text { que se citará en } \\
\text { adelante }\end{array}$ \\
\hline $\begin{array}{c}\text { Caperucita sin } \\
\text { Cuentos }\end{array}$ & $\begin{array}{c}\text { Sebastián } \\
\text { Burecovics } \\
\end{array}$ & Luz Igolnikow & Español & $\begin{array}{c}\text { Ediciones Infantil (Arg.) } \\
-2015 \\
\end{array}$ & $\operatorname{CsC}$ \\
\hline Una caperucita roja & Marjolaine Leray & Marjolaine Leray & Francés & Océano (Arg.) - 2009 & $U C R$ \\
\hline Pobre lobo & Ema Wolf & Matías Trillo & Español & Alfaguara (Arg.) - 2013 & $P L$ \\
\hline $\begin{array}{c}\text { Lo que no vio } \\
\text { Caperucita }\end{array}$ & Mar Ferrero & Mar Ferrero & Español & Edelvives (Arg.) - 2014 & $N V C$ \\
\hline $\begin{array}{c}\text { Lobo rojo y } \\
\text { Caperucita feroz }\end{array}$ & Elsa Bornemann & Cynthia Orensztajn & Español & Loqueleo (Arg.) - & $L R C F$ \\
\hline La niña de rojo & Aaron Frisch & Roberto Innocenti & Inglés & Kalandraka - 2013 & $N R$ \\
\hline Caperucita Roja & Adolfo Serra & Adolfo Serra & Español & FCE (Méx.) - 2017 & $C R-A S$ \\
\hline $\begin{array}{l}\text { Little Red Riding } \\
\text { Hood and the Wolf }\end{array}$ & Roald Dahl & Quentin Blake & Inglés & Penguin (EEUU) - 2009 & $L R R H W$ \\
\hline $\begin{array}{c}\text { Detective John } \\
\text { Chatterton } \\
\end{array}$ & Yvan Pommaux & Yvan Pommaux & Francés & $\begin{array}{l}\text { Ediciones Ekaré (Ven.) - } \\
2002 \\
\end{array}$ & $D J C$ \\
\hline La Caperucita Roja & Perrault & Leticia Gotlibowski & Español & $\begin{array}{c}\text { Ediciones del Eclipse } \\
(\text { Arg. })-2008\end{array}$ & $L C R$ \\
\hline El plan & Ethel Batista & Eva Mastrogiulio & Español & $\begin{array}{l}\text { Calibroscopio (Arg.) - } \\
2019 \\
\end{array}$ & $E P$ \\
\hline Las tres cerditas & Fredéric Stehr & Fredéric Stehr & Francés & Corimbo (Esp.) - 2006 & $T C-F S$ \\
\hline Los tres cerditos & David Wiesner & David Wiesner & Inglés & $\begin{array}{l}\text { Ed. Juventud (Esp.) - } \\
2015\end{array}$ & $T C-D W$ \\
\hline $\begin{array}{l}\text { Los tres chanchitos } \\
\text { madre de visita }\end{array}$ & $\begin{array}{c}\text { Sebastián } \\
\text { Burecovics }\end{array}$ & Luz Igolnikow & Español & $\begin{array}{l}\text { Ediciones Infantil (Arg.) } \\
-2015\end{array}$ & $T C M V$ \\
\hline The three Little Pigs & Roald Dahl & Quentin Blake & Inglés & Penguin (EEUU) - 2009 & $T L P$ \\
\hline $\begin{array}{l}\text { El Príncipe } \\
\text { Ceniciento }\end{array}$ & Babette Cole & Babette Cole & Inglés & $\begin{array}{c}\text { Ediciones Destino (Esp.) } \\
-1998\end{array}$ & $P C$ \\
\hline $\begin{array}{c}\text { La del zapatito de } \\
\text { cristal }\end{array}$ & Cecilia Pisos & Federico Combi & Español & Quispe (Arg.) - 2012 & $Z C$ \\
\hline Cinderella & Roald Dahl & Quentin Blake & Inglés & Penguin (EEUU) - 2009 & $\mathrm{Ci}$ \\
\hline $\begin{array}{c}\text { Blancanieves un } \\
\text { espejo enamorado }\end{array}$ & $\begin{array}{c}\text { Sebastián } \\
\text { Burecovics }\end{array}$ & Luz Igolnikow & Español & $\begin{array}{l}\text { Ediciones Infantil (Arg.) } \\
-2015 \\
\end{array}$ & $B E E$ \\
\hline $\begin{array}{c}\text { Y comieron } \\
\text { perdices... ;todos } \\
\text { los días! }\end{array}$ & Inés Falconi & Federico Combi & Español & Quispe (Arg.) - 2012 & $C P T D$ \\
\hline $\begin{array}{l}\text { Snow-White and the } \\
\text { Seven Dwarfs }\end{array}$ & Roald Dahl & Quentin Blake & Inglés & Penguin (EEUU) - 2009 & $S W S D$ \\
\hline Lila & Yvan Pommaux & Yvan Pommaux & Francés & Ediciones Ekaré (Ven.) & $\mathrm{Li}$ \\
\hline La durmiente & $\begin{array}{c}\text { María Teresa } \\
\text { Andruetto }\end{array}$ & Istvansch & Español & Loqueleo (Arg.) - 2019 & $L D$ \\
\hline $\begin{array}{c}\text { El sueño } \\
\text { interminable }\end{array}$ & Yvan Pommaux & Yvan Pommaux & Francés & Ediciones Ekaré & $S I$ \\
\hline Hansel y Gretel & $\begin{array}{c}\text { Roberto } \\
\text { Fontanarrosa } \\
\end{array}$ & $\begin{array}{c}\text { Roberto } \\
\text { Fontanarrosa } \\
\end{array}$ & Español & $\begin{array}{l}\text { Ediciones de la Flor } \\
\text { (Arg.) }\end{array}$ & $H G-R F$ \\
\hline $\begin{array}{l}\text { Hansel y Gretel un } \\
\text { mal negocio }\end{array}$ & $\begin{array}{c}\text { Sebastián } \\
\text { Burecovics }\end{array}$ & Luz Igolnikow & Español & $\begin{array}{l}\text { Ediciones Infantil (Arg.) } \\
-2015\end{array}$ & $H G M N$ \\
\hline
\end{tabular}




\section{Criterios de análisis}

Los criterios de análisis se apoyaron en una selección de estrategias de reescritura que dan lugar a recurrencias y desvíos de la línea argumental original, planteando una relación intertextual fecunda, que puede diversificarse sin fin. Como base teórica para sistematizar las principales transformaciones que observamos en algunas de las reescrituras tomamos algunos aspectos mencionados por Colomer (1996) y también la clasificación propuesta por Zavala (1999) para el análisis de elementos intertextuales.

Las principales transformaciones que observamos en algunas de las reescrituras analizadas son:

1. Alteraciones en la estructura y secuencia narrativa de los relatos. Éstas pueden conducir a que se retome algún personaje, una escena o una idea reconocibles en un contexto narrativo diferente.

2. Inversión o cambios en los roles de los personajes: de buenos a malos, de secundarios a protagonistas, de débiles a fuertes, de poderoso a débil, son algunas de las posibilidades de esta estrategia. También, se pueden incorporar rasgos nuevos a la personalidad de los personajes, sin que necesariamente intercambie su rol con otro.

3. Introducción de nuevos puntos de vista: en la narración de la historia adquieren voz y visibilidad personajes que antes no la tenían abriendo perspectiva sobre la historia conocida.

4. Incorporación de la autorreferencia literaria ya sea citando otros textos en la historia, deconstruyendo el concepto de libro, incluyendo epílogos o comentarios que hacen referencia al carácter ficticio de la historia. En general, todas las reescrituras son autorreferenciales e intertextuales; pero en algunas de ellas este rasgo se subraya con estrategias que apelan al humor y la complicidad del lector más allá de la referencialidad propia de la reescritura.

5. Juego con el género que convierte al relato tradicional en historieta o cinta cinematográfica representada en el formato papel.

6. Actualización del contexto e introducción de nuevos paradigmas: puede estar marcada por el cambio de roles de los personajes, por el cambio de género de los personajes, por una alteración en la resolución de los conflictos, por la introducción de temas de interés actual (derechos de los niños/as, de los animales, ecología), por referencias al vestuario, la música, la tecnología y otros aspectos reconocibles en el presente.

7. Incorporación de nuevos sentidos a partir del tratamiento de la imagen.

Cada uno de estos tipos de transformación opera en dos niveles: a nivel textual o formal, la historia que se cuenta y cómo se cuenta es diferente; a nivel ideológico, moral o filosófico: las significaciones que se abren son diferentes.

\section{Análisis del corpus}

El análisis del corpus muestra que las estrategias de reescritura no se dan de forma aislada sino que muchas veces se solapan y conviven en un mismo texto. A continuación, se exponen las estrategias identificadas en cada relato del corpus. Asimismo, se subrayan los rasgos sobresalientes en términos del potencial de intertextualidad y producción de sentidos.

\section{Caperucita Roja}

Como se observa en la Tabla 2, prevalece el cambio o inversión de roles. 
Tabla 2: estrategias en las reescrituras de Caperucita Roja

\begin{tabular}{|c|c|c|c|c|c|c|c|}
\hline & $\begin{array}{c}\text { Alteraciones } \\
\text { en la } \\
\text { secuencia } \\
\text { del relato }\end{array}$ & $\begin{array}{c}\text { Cambios de } \\
\text { roles }\end{array}$ & $\begin{array}{l}\text { Nuevos } \\
\text { puntos de } \\
\text { vista }\end{array}$ & $\begin{array}{c}\text { Autorrefere } \\
\text { ncia } \\
\text { literaria / } \\
\text { Intertextual } \\
\text { idad } \\
\text { explícita }\end{array}$ & $\begin{array}{l}\text { Juego con el } \\
\text { género }\end{array}$ & $\begin{array}{c}\text { Actualizació } \\
\text { n del } \\
\text { contexto }\end{array}$ & $\begin{array}{l}\text { Sentidos de } \\
\text { la imagen }\end{array}$ \\
\hline $\operatorname{CsC}$ & --- & $\begin{array}{c}\text { Lobo } \\
\text { colaborador }\end{array}$ & Abuela & --- & --- & --- & --- \\
\hline$U C R$ & Única escena & $\begin{array}{c}\text { Niña } \\
\text { vengativa }\end{array}$ & --- & --- & --- & $\begin{array}{c}\text { Tono } \\
\text { feminista }\end{array}$ & $\begin{array}{c}\text { Colores para } \\
\text { cada } \\
\text { personaje }\end{array}$ \\
\hline$P L$ & $\begin{array}{c}\text { Única escena } \\
\text { / Distinto } \\
\text { final }\end{array}$ & $\begin{array}{c}\text { Niña burlona } \\
\text { / lobo } \\
\text { desvalido }\end{array}$ & --- & --- & --- & --- & --- \\
\hline$L N V C$ & $\begin{array}{c}\text { Fragmentada } \\
\text { / Distinto } \\
\text { final }\end{array}$ & $\begin{array}{c}\text { Lobo } \\
\text { desvalido / } \\
\text { Abuela } \\
\text { cómplice } \\
\end{array}$ & $\begin{array}{c}\text { Caperucita, } \\
\text { abuela, lobo } \\
\text { y animales } \\
\text { del bosque }\end{array}$ & --- & --- & --- & --- \\
\hline$L R C F$ & $\begin{array}{c}\text { Nueva } \\
\text { narración }\end{array}$ & $\begin{array}{c}\text { Niña } \\
\text { malvada / } \\
\text { lobo } \\
\text { asustado } \\
\end{array}$ & $\begin{array}{c}\text { Animales del } \\
\text { bosque }\end{array}$ & --- & --- & $\begin{array}{c}\text { Tema } \\
\text { ecológico }\end{array}$ & --- \\
\hline$N R$ & --- & --- & --- & --- & Historieta & $\begin{array}{c}\text { Espacio } \\
\text { contemporán } \\
\text { eo / } \\
\text { Violencia }\end{array}$ & $\begin{array}{c}\text { Ámbito } \\
\text { urbano / } \\
\text { Actualizació } \\
\text { n del } \\
\text { contexto }\end{array}$ \\
\hline$C R-A S$ & --- & --- & --- & --- & --- & --- & $\begin{array}{c}\text { El lobo es el } \\
\text { camino y el } \\
\text { bosque }\end{array}$ \\
\hline$D J C$ & $\begin{array}{l}\text { El nudo del } \\
\text { relato } \\
\text { tradicional se } \\
\text { incorpora en } \\
\text { el relato del } \\
\text { caso policial }\end{array}$ & --- & Detective & $\begin{array}{l}\text { Citas del } \\
\text { relato } \\
\text { tradicional }\end{array}$ & $\begin{array}{l}\text { Policial / } \\
\text { Historieta }\end{array}$ & --- & $\begin{array}{l}\text { Ámbito } \\
\text { urbano }\end{array}$ \\
\hline$L R R H W$ & --- & $\begin{array}{l}\text { Caperucita } \\
\text { asesina }\end{array}$ & --- & --- & --- & --- & $\begin{array}{l}\text { Actualiza- } \\
\text { ción del } \\
\text { contexto }\end{array}$ \\
\hline$L C R$ & --- & --- & --- & --- & --- & --- & $\begin{array}{c}\text { Intertextuali- } \\
\text { dad con artes } \\
\text { plásticas }\end{array}$ \\
\hline
\end{tabular}

Fuente: elaboración propia

Es posible que la imagen de la niña ingenua e indefensa del cuento tradicional inspire la rebeldía feminista que hace de Caperucita un personaje astuto y hasta temible en estas reescrituras. El feminismo subyacente es claro en $U C R$. Es la niña quien convida un caramelo envenenado al lobo y pronuncia un simple "Ingenuo" ( $\mathrm{s} / \mathrm{n})$ cuando éste muere. Así, las mujeres indefensas de la versión tradicional (la abuela y la niña) se convierten en rivales o en cómplices de un lobo que el lector conoce ya como peligroso, pero que sorprende por su indefensión en la reescritura. Al igual que en reescrituras de otros cuentos, la abuela actúa en complicidad o amistad con el lobo (CsC; $L N V C$ respectivamente). Caperucita, en cambio, aparece como rival digna de la ferocidad del lobo $(U C R ; L R R H W)$, como una cazadora de animales $(C F L R)$, o una niña despreocupada que desconoce la trama que tejen los demás personajes pero sale ilesa del eventual peligro $(L N V C ; P L ; C s C)$. En la mayoría de estas reescrituras, el cambio de roles provoca un efecto humorístico. La única que tiene un mensaje implícito es CFLR con su subtono ecologista y, sobre todo, que los malos siempre reciben su lección, a modo de corregir sus acciones incorrectas.

Un ejemplo interesante por la polifonía que acompaña al cambio de puntos de vista es $L N V C$. En este texto, la historia se construye en capítulos, cada uno con las perspectivas de la niña, el lobo, los animales del bosque, y la abuela. Esta polifonía implica una riqueza estética que se suma al disfrute de la desestabilización que produce la reescritura. Otro caso son las reescrituras que, aunque se apegan a la historia tradicional, presentan un tratamiento novedoso 
a través de la imagen: en $L N R$ la acción se sitúa en un contexto urbano y en $C R-A S$ el lobo deviene en bosque. En $U C R$, los personajes aparecen sobre un fondo blanco, Caperucita y su texto en color rojo, el lobo y su texto en color negro. También en $C R-A S$ los colores son rojo y negro sobre un fondo blanco. En $C R-L G$ se presenta una compleja resemantización del relato a través de imágenes asociadas a Francia, la época de la revolución y María Antonieta, acompañando el texto de Perrault.

Un caso particular en el que se modifica el género literario es en la reescritura de Pommaux. $D J C$ se trata de una historieta policial, en la que un detective gato sigue las pistas para encontrar a la niña de rojo perdida. El detective menciona que este caso le recuerda a "la triste historia en donde una niña y su abuela son devoradas por un lobo" (s/n), explicitando el diálogo o la intertextualidad con el relato tradicional. El detective también recuerda que en esa historia hay un cazador que las salva y podemos pensar que el gato detective ocupará ese lugar. Toda la estructura de la historieta responde a las típicas características de un relato policial: se presenta un enigma a resolver y el detective, a través de una serie de pistas, logra encontrar al secuestrador y restablece un orden, que en la historia sería un final feliz.

Cabe resaltar que el el conocido diálogo entre Caperucita y el lobo, es un elemento de la línea argumental que se reitera, tal vez por su centralidad en el argumento del cuento tradicional, en el que este pasaje lleva al clímax o al punto de más intensidad en la historia. En cada caso, tiene una cualidad particular: en $L N V$, la niña dialoga con el lobo bajo la mirada de la abuela, que descubre así su miopía; en $P L$, casi se diría que la niña hace bullying al lobo; en $C F L R$, es Caperucita quien se disfraza de la abuela del lobo; en $U C R$, Caperucita ofrece el caramelo al lobo cuando éste abre la boca luego del "es para comerte mejor", y la joven de $C R L F$ exclama "iQué hermoso saco de piel tienes puesto!" (p. 38, nuestra traducción), saca un arma, mata al lobo y se hace un tapado.

\section{Los tres cerditos}

A diferencia de los otros cuentos tradicionales que aquí se analizan, en Los tres cerditos las víctimas terminan vengándose de su victimario. El mensaje del relato se centra, así, en los efectos nocivos de la pereza y la despreocupación de los dos primeros cerditos en contraste con la industria del tercero. Como se observa en la Tabla 3, sólo una reescritura utiliza la estrategia de inversión de roles.

Tabla 3: estrategias en las reescrituras de Los tres cerditos

\begin{tabular}{|c|c|c|c|c|c|c|c|}
\hline & $\begin{array}{l}\text { Alteraciones en } \\
\text { la secuencia del } \\
\text { relato }\end{array}$ & $\begin{array}{l}\text { Cambios de } \\
\text { roles }\end{array}$ & $\begin{array}{c}\text { Nuevos } \\
\text { puntos de } \\
\text { vista }\end{array}$ & $\begin{array}{l}\text { Autorreferencia } \\
\text { literaria/ } \\
\text { Intertextualidad } \\
\text { explícita }\end{array}$ & $\begin{array}{l}\text { Juego } \\
\text { con el } \\
\text { género }\end{array}$ & $\begin{array}{l}\text { Actualización } \\
\text { del contexto }\end{array}$ & $\begin{array}{l}\text { Sentidos de la } \\
\text { imagen }\end{array}$ \\
\hline$E P$ & Epílogo & --- & --- & $\begin{array}{l}\text { Personajes leen su } \\
\text { libro }\end{array}$ & --- & $\begin{array}{c}\text { Rol femenino/ } \\
\text { Protagonistas } \\
\text { mujeres }\end{array}$ & $\begin{array}{l}\text { Actualización del } \\
\text { contexto }\end{array}$ \\
\hline$L T C-F S$ & Cambia el final & --- & --- & --- & --- & $\begin{array}{l}\text { Tono feminista } \\
\text { Protagonistas } \\
\text { mujeres }\end{array}$ & --- \\
\hline $\begin{array}{l}L T C- \\
D W\end{array}$ & Nueva narración & --- & $\begin{array}{l}\text { Nuevos } \\
\text { personajes }\end{array}$ & $\begin{array}{c}\text { Personajes recorren el } \\
\text { libro }\end{array}$ & --- & --- & $\begin{array}{l}\text { Autorreferencia / } \\
\text { Diálogo con el } \\
\text { lector }\end{array}$ \\
\hline LTCMV & Nuevas escenas & $\begin{array}{l}\text { Lobo bueno/ } \\
\text { Madre } \\
\text { posesiva }\end{array}$ & Madre & --- & --- & --- & --- \\
\hline $\begin{array}{l}L T C- \\
R D\end{array}$ & Nuevas escenas & $\begin{array}{l}\text { Chanchito no } \\
\text { es valiente ni } \\
\text { ingenioso }\end{array}$ & --- & $\begin{array}{l}\text { Caperucita como } \\
\text { personaje }\end{array}$ & --- & --- & $\begin{array}{l}\text { Actualización del } \\
\text { contexto }\end{array}$ \\
\hline
\end{tabular}

Fuente: elaboración propia 
Sólo en $T C M V$ el lobo es bueno. En las demás reescrituras, el lobo persigue para comer a los cerditos/as pero, al igual que en la historia tradicional, es superado en ingenio por sus víctimas.

Cabe subrayar la inversión de género en EP y $L T C-F S$, cuyas protagonistas son mujeres, y retoman la historia desde una perspectiva feminista. En EP las imágenes presentan una gran actualidad y rompen con el estereotipo femenino tradicional determinados en otros momentos para las mujeres: la contextura de los cuerpos, los peinados y los cortes de cabello, el uso de tatuajes, piercings y accesorios como el skate. Con esto, se establece un diálogo entre textos de diversas épocas y se manifiesta una renovación cultural con nuevos paradigmas y nuevas representaciones de las mujeres en la literatura infantil. En el relato, las acciones del lobo se corresponden con la línea argumental del cuento tradicional. Pero, a pesar de mostrarse ideando un plan, se ve desconcertado ante cada situación nueva que se le presenta y "termina haciendo las mismas cosas de siempre" (p. 17). En este sentido, es un personaje que no se renueva; en contraste, las cerditas son conscientes de los cambios que están haciendo en la historia.

Por su parte, $L T C-F S$, si bien toma la idea de los tres cerditos que viven en diversas casas, el lobo no sopla para tratar de comerse a las cerditas sino que utiliza una técnica mejorada: se disfraza de un apuesto cerdo. Como la madre les había dicho que busquen al mejor marido posible, dos de las cerditas caen en la trampa del lobo disfrazado. De esta manera, se invierte el mensaje de obediencia al mandato social/materno: sólo sobrevive la cerdita que no busca casarse, como un empoderamiento de la mujer. Ésta hace justicia por las demás y engaña al lobo disfrazándose de lobo y conduciendo al lobo disfrazado de cerdo a encontrarse con otro lobo de verdad.

En esta reescritura también cobran relevancia las imágenes: a través de ellas se ve que, a diferencia del cuento tradicional, el lobo comienza buscando su víctima en la casa más resistente (la de ladrillos), luego continúa por la de madera, y la única que logra engañarlo y capturarlo es la chanchita de la casa más débil, la de paja. Esto redobla el desafío al mensaje original que subraya el valor del cerdito más trabajador y subvierte la imagen de la mujer preocupada principalmente por su casa.

Con respecto a las autorreferencias literarias, al final de la historia de $E P$, a modo de álbum o de libro de viaje, aparecen imágenes de las chanchitas haciendo actividades recreativas: viajando, compitiendo con el skate, leyendo. Una de las lecturas es el mismo libro que las contiene, es decir leen El plan. No obstante, el texto más interesante y complejo desde este punto de vista, es $L T C-D W$. Si bien el título y el inicio de la lectura no adelantan una renovación estética o cultural, relato e imagen construyen perspicazmente una reescritura del cuento que habla de él mismo.

En principio, el lobo (que sigue siendo feroz en el primer momento) sopla tan fuerte una de las casitas que arroja a los chanchitos fuera del cuento. A partir de allí, los cerditos comienzan a pasear por las páginas del libro y de otros libros de cuentos, incluso del propio relato tradicional que les da vida. En un momento, uno de los cerdos apela al lector, promoviendo que éste tome conciencia de su rol y, al mismo tiempo, haciéndolo partícipe de la historia. Nos damos cuenta por el comentario pero, sobre todo, por la imagen (la cara del cerdito ocupa toda una página y parece mirarnos, pág.22). Por otro lado, hay una intertextualidad densa dado que los tres hermanos van rescatando personajes de otros cuentos (un dragón, un gato), que serán los ayudantes de la acción final en la que el lobo es capturado por todos los personajes y hecho sopa. Uno de los cerditos se encarga de escribir el final, acomodando las letras capturadas a lo largo de las hojas: "y todos vivieron felices para siempre", frase característica de los cuentos tradicionales con finales felices. En esta reescritura, el final feliz es para los cerditos y el ingenio de los chanchitos ya no está en construir una casa fuerte, sino en construir una historia diferente. 
La intertextualidad también es un rasgo sobresaliente en $L T C-R D$. En esta ocasión, el tercer cerdito (único hermano sobreviviente) llama por teléfono a Caperucita porque sabe que ya se ha deshecho de un lobo en su propia historia. El cuento termina con una Caperucita que lleva en sus viajes dos tapados de piel de lobo y una maleta de piel de cerdo, y una 'moraleja': "Ah, Cerdito, nunca confíes en jóvenes de la alta sociedad..." (p. 47, nuestra traducción).

Por último, se puede subrayar que las famosas líneas del lobo "chanchito, chanchito déjame entrar" y "soplaré, soplaré y la casa derribaré" se repite en casi todas las reescrituras. Al igual que el diálogo entre Caperucita y el lobo, es una referencia ineludible que resalta las novedades de la reescritura.

\section{Cenicienta, Blancanieves, La Bella durmiente, Hansel y Gretel}

En este conjunto de reescrituras, la mayoría mantiene la secuencia del relato tradicional, salvo ZC y B que son lo que se puede denominar una secuela del relato (de hecho, el título de la antología que contiene éstas y otras reescrituras se titula Había una vez y después). Pero, probablemente, de todas las reescrituras analizadas, en las de Cenicienta y Blancanieves, lo más interesante para destacar son los cambios de paradigmas y la actualización del contexto. Como se puede observar en la Tabla 4, en todas hay una una inversión de roles, ya sea de personajes femeninos a masculinos, de personajes malvados que ocupan el lugar de buenos, como también de personajes tradicionales que ahora descubrimos en una nueva faceta, libre de estereotipos como en el caso de $Z C$ :

Tabla 4: estrategias en las reescrituras de Cenicienta

\begin{tabular}{|c|c|c|c|c|c|c|c|}
\hline & $\begin{array}{c}\text { Alteraciones en } \\
\text { la secuencia del } \\
\text { relato }\end{array}$ & Cambios de roles & $\begin{array}{l}\text { Nuevos } \\
\text { puntos de } \\
\text { vista }\end{array}$ & $\begin{array}{c}\text { Autorrefe- } \\
\text { rencia literaria / } \\
\text { Intertextualidad } \\
\text { explícita } \\
\end{array}$ & $\begin{array}{l}\text { Juegos con } \\
\text { el género }\end{array}$ & $\begin{array}{l}\text { Actualiza- } \\
\text { ción del } \\
\text { contexto }\end{array}$ & $\begin{array}{l}\text { Sentidos de } \\
\text { la imagen }\end{array}$ \\
\hline$P C$ & --- & --- & --- & --- & --- & $\begin{array}{l}\text { Ceninciento } \\
\text { es varón / } \\
\text { Princesa } \\
\text { mujer } \\
\end{array}$ & $\begin{array}{c}\text { Actualización } \\
\text { del contexto }\end{array}$ \\
\hline$Z C$ & Secuela del relato & $\begin{array}{c}\text { Príncipe ingenuo / } \\
\text { Cenicienta no } \\
\text { deviene princesa } \\
\end{array}$ & Madrastra & $\begin{array}{l}\text { Citas al relato } \\
\text { tradicional }\end{array}$ & --- & $\begin{array}{c}\text { Temas } \\
\text { actuales }\end{array}$ & --- \\
\hline $\mathrm{Ci}$ & Cambia el final & $\begin{array}{l}\text { Príncipe malvado / } \\
\text { Cenicienta no } \\
\text { deviene princesa }\end{array}$ & --- & --- & --- & --- & $\begin{array}{l}\text { Actualización } \\
\text { del contexto }\end{array}$ \\
\hline$B E E$ & Nuevas escenas & --- & Espejo & --- & --- & $\begin{array}{l}\text { Estereotipo de } \\
\text { belleza }\end{array}$ & --- \\
\hline$C P T D$ & Secuela & $\begin{array}{c}\text { Príncipe } \\
\text { decepcionante }\end{array}$ & --- & $\begin{array}{c}\text { Citas al relato } \\
\text { tradicional }\end{array}$ & --- & $\begin{array}{c}\text { Temas } \\
\text { actuales }\end{array}$ & --- \\
\hline$L i$ & $\begin{array}{l}\text { El nudo del relato } \\
\text { tradicional se } \\
\text { incorpora en una } \\
\text { nueva historia y } \\
\text { en el relato del } \\
\text { caso policial } \\
\end{array}$ & --- & Detective & $\begin{array}{l}\text { Citas del relato } \\
\text { tradicional }\end{array}$ & $\begin{array}{l}\text { Policial / } \\
\text { Historieta }\end{array}$ & --- & $\begin{array}{l}\text { Ámbito } \\
\text { urbano }\end{array}$ \\
\hline$S W S D$ & Cambia el final & $\begin{array}{c}\text { Blancanieves } \\
\text { astuta / Enanos } \\
\text { jugadores } \\
\end{array}$ & --- & --- & --- & $\begin{array}{c}\text { Temas } \\
\text { actuales }\end{array}$ & $\begin{array}{c}\text { Actualización } \\
\text { del contexto }\end{array}$ \\
\hline$L D$ & Nueva narración & $\begin{array}{c}\text { Princesa } \\
\text { revolucionaria }\end{array}$ & --- & --- & ---- & $\begin{array}{l}\text { Tono } \\
\text { feminista }\end{array}$ & $\begin{array}{c}\text { Artes } \\
\text { plásticas- } \\
\text { collage }\end{array}$ \\
\hline$S I$ & $\begin{array}{c}\text { El nudo del relato } \\
\text { tradicional se } \\
\text { incorpora en el } \\
\text { relato del caso } \\
\text { policial } \\
\end{array}$ & --- & Detective & $\begin{array}{l}\text { Citas del relato } \\
\text { tradicional }\end{array}$ & $\begin{array}{l}\text { Policial / } \\
\text { Historieta }\end{array}$ & --- & $\begin{array}{l}\text { Ámbito } \\
\text { urbano }\end{array}$ \\
\hline$H G-R F$ & Cambia el final & $\begin{array}{c}\text { La madre se } \\
\text { alegra al } \\
\text { encontrarlos / los } \\
\text { niños no quieren } \\
\text { regresar }\end{array}$ & --- & $\begin{array}{l}\text { Referencias al } \\
\text { cuento } \\
\text { tradicional }\end{array}$ & Historieta & --- & --- \\
\hline$H G M N$ & Nueva narración & $\begin{array}{c}\text { Niños malvados / } \\
\text { bruja buena }\end{array}$ & --- & --- & --- & $\begin{array}{c}\text { Temas } \\
\text { actuales }\end{array}$ & --- \\
\hline
\end{tabular}


En $Z C$, la novedad está en la inversión de roles dado que fue la madrastra quien se casó con el príncipe y Cenicienta siguió siendo la sirvienta de la casa. Este secreto es revelado en una entrevista que da la madrastra cuando ya es anciana y el príncipe está muerto, y sorprende doblemente al lector cuando, al final del cuento, la madrastra identifica a Cenicienta para los reporteros: "ya la vieron, ¿se dan cuenta? La vieron y no la vieron, igual que el Príncipe: es la anciana que les abrió la puerta". Esta estrategia tiene múltiples dimensiones. Por un lado, es una actualización del contexto dado que la supuesta Cenicienta aparece como un personaje de la farándula $\mathrm{y}$, por algunas frases y lugares que se mencionan, vive en Argentina. Por otro lado, contiene múltiples referencias literarias al cuento tradicional y a otras reescrituras, incluidas las producciones de Disney que no reproducen escenas exactas, "pero eso pasa en muchas películas y con muchos libros" (p. 24). Por último, hay una actualización en la forma de entender el amor:

rompe con el mito según el cual las almas se reconocen entre sí por su nobleza de modo que los malos no engañan a los buenos, que perciben en su fuero íntimo la maldad de los espíritus y no confunden la belleza corporal con la belleza del alma. Por último, rompe con la idea de que las 'pruebas' no son meras evidencias empíricas (como el calce de un zapatito) sino muestras de grandeza espiritual que trascienden las apariencias y se imponen con una certeza superior. (Pac et al, 2017, p. 63)

Por último, esta reescritura, al igual que $C i$, rompe con el objeto mágico como rasgo estructural de los cuentos de hadas. La madrastra pudo calzar el zapato de cristal en $C Z$, y una de las hermanas también lo calza en $\mathrm{Ci}$. En este caso, a diferencia de la versión conocida, el zapato se describe como largo y ancho, y un poco oloroso. El ideal de belleza femenina que representaba el zapatito de cristal es así puesto en duda, así como el ideal del príncipe esperado (en $\mathrm{Ci}$ ) es un hombre violento que corta las cabezas de las hermanas para no cumplir su palabra, del que Cenicienta se esconde y con quien no se casa).

La actualización del contexto en la secuela $C P T D$ muestra a una princesa que no vive feliz para siempre, sino que se divorcia. No obstante, no sería posible identificar en este divorcio una figura femenina fortalecida como se ha señalado en otras reescrituras. Esta Blancanieves se resiente porque "Pupi", su marido, apenas le presta atención y la deja sola en el castillo, en donde se aburre. Finalmente, vuelve a vivir con los enanos y hacer las tareas domésticas para ellos. A pesar de no romper con este aspecto del estereotipo femenino, se puede señalar en esta versión la misma desmitificación del amor que se encuentra en ZC:

En la reescritura de Falconi, esta princesa tampoco lleva la realeza 'en la sangre' o 'en el alma' (a pesar de ser, al inicio de la historia tradicional, hija de un rey). Por otra parte, el punto de apoyo de 'la felicidad eterna', a saber, la figura del príncipe como 'rescatista' o 'salvador', se manifiesta en toda su fragilidad o, mejor dicho, su falsedad. El desamor, la indiferencia, la vida cotidiana irrumpen en el 'cuento de hadas' tal como lo hacen en la 'vida real'. De esta manera, se produce una ruptura con la idealización del amor romántico que cuentos y películas reiteran hasta el cansancio, y se introduce la posibilidad del error en la identificación que, al igual que en la Cenicienta de Pisos, resultó fallida. (Pac et al, 2017, p. 64)

La Blancanieves de $B S E$, por su parte, también se queda a vivir con los hombrecitos que son ex-jockeys y apostadores compulsivos a las carreras de caballos. Pero no se queda con ellos para atenderlos sino que logra robar el espejo mágico de su madrastra para que les adelante el resultado de las carreras. De este modo, Blancanieves y sus hombrecitos viven millonarios y felices. Esta ruptura con la secuencia tradicional del relato, lo convierte en un ejercicio lúdico y estético-literario.

También en $P C$ podemos destacar la actualización del contexto: la fiesta no tiene lugar en un palacio sino en una discoteca, y los personajes se encuentran en una parada de autobuses. El objeto que hace posible el reconocimiento no es un zapato de cristal sino un jean, que se 
vuelve otro elemento actualizador del contexto (también en las ilustraciones de todas las reescrituras de Roald Dahl, Cenicienta y Blancanieves visten jeans). Pero, sobre todo, se destaca la inversión de género cambiando a las mujeres por hombres no sólo en el personaje principal (Ceniciento por Cenicienta) sino también a las hermanastras por hermanastros y el príncipe por una princesa. Este universo masculino, se puede analizar en la construcción de los personajes, algunos de los estereotipos comunes de los hombres: los fuertes y musculosos versus los más pequeños y débiles. El hombre fuerte, bello, deseable que se supone que debería ser el príncipe, se cambia por uno estéticamente distinto. Incluso, la fuerza como uno de los deseos que pide el príncipe a su hada madrina es un recurso humorístico que ridiculiza el estereotipo del varón. Ceniciento pide ser "fuerte y peludo" y por eso el hada (cuyos hechizos fallan) lo convierte en un orangután.

Así como en $Z C$, el cambio de roles es también una estrategia frecuente. En $B E E$, como en todos los relatos de la colección de Burecovics, podemos ver la inversión de roles y el cambio de perspectiva de la narración. El espejo, enamorado de la reina del palacio, decide enemistarla con la niña Blancanieves, por ello, crea un plan que no sale acorde a lo esperado. Si bien el resto de la historia es conocida, lo que analizamos es el cambio de narrador, el cambio de roles: Blancanieves es una niña fea y asiste a la peluquería para mejorar su look mientras que la madrastra es una mujer muy bella.

También en las reescrituras de Hansel y Gretel hay un cambio de roles. En $H G M N$, los niños son voraces y malvados que acusan falsamente a la bruja, quien es una emprendedora que busca quienes la ayuden a promocionar su negocio (la casa hecha con golosinas). Esto último implica también una actualización del contexto, con su referencia al marketing. En $H G-R F$, los niños ponen una parrilla en la casa de la bruja (que no es manifiestamente mala, no intenta comerlos y al final del relato no se explicita qué ha sucedido con ella) y se niegan a volver con sus padres cuando éstos los encuentran. En esta última reescritura, es de subrayar el cambio de género a la historieta, el uso del lenguaje. Los personajes remedan un lenguaje anticuado. Esta artificialidad junto con referencias intertextuales al relato tradicional (un cartel que indica To Grimm brothers' house) y a temas que producen un efecto absurdo (el pavimento, los indios, la contaminación en el bosque) producen un efecto de extrañamiento similar al de la autorreferencia literaria.

La intertextualidad también adopta este efecto humorístico y de extrañamiento en $\mathrm{Li}$. Lilia (Blancanieves) no está escondida en la casa de los enanos sino en la casa de su novio. Pero la referencia a los enanos del relato tradicional aparece en el regalo que recibe el detective cuando resuelve el caso: un enano de jardín que trajo de uno de sus viajes. El detective agrega: "Él tiene otras seis, casi idénticas a esta. Son los personajes de un viejo caso bastante conocido que, en algunos detalles, se parece al de Lilia". En todos los casos de Chatterton, la referencia al cuento tradicional recuerda al lector que está leyendo otra historia.

En $L D$ lo particular se presenta en el cambio de la narración: si bien no sigue la historia del cuento tradicional, el cambio más evidente se vislumbra en que la princesa se duerme para no ver las injusticias del castillo donde vive: hambrunas, desigualdad social, injusticias: "Y vio que la vida era esto: una vieja muy vieja hurgando unos restos, un niño perdido, una casa con hambre, por almuerzo unas papas" (p. 22); pero finalmente despierta por el estallido de la revolución. En este tono de mujer empoderada, también se destaca la relación del texto con las imágenes ya que, por un lado, las que están en blanco y negro representan la narración, por otro lado, se puede apreciar un collage con pinturas de artistas reconocidos (Delacroix, Velázquez, Berni, De la Cárcova) que evidencian algunos de los temas por los que la princesa duerme y se niega a ver la realidad. Asimismo, en ese collage artístico se pueden observar fragmentos de noticias o textos que representan a un estereotipo de mujer bajo los estándares de belleza aceptados por las distintas décadas, un prototipo de mujer ama de casa, buena esposa y bella. Por ello, podríamos pensar que la princesa también duerme: no quiere ver la 
condición de las mujeres en el contexto en el que le toca vivir y que parte de la revolución es también de la mujer.

En SI el nudo tradicional se incorpora en el relato del caso resuelto por el detective. La historia de la señorita Rosepin es la de Aurora. Sólo que el relato policial y las ilustraciones de la historieta renuevan el contexto. La manera cómo se pincha con el huso de la rueca en una tienda de antigüedades y el detective que lee un libro de casos famosos para saber que tiene que buscar al "elegido de su corazón" para que la despierte, son estrategias que reescriben la historia y, como se señaló con respecto a las otras reescrituras de Pommeaux, subrayan la intertextualidad para producir un extrañamiento necesario para la estética literaria.

\section{CONCLUSIÓN}

Las reescrituras de los cuentos tradicionales son una marca de nuestra época. Cualquiera sea su expresión (literaria, cinematográfica, teatral, hecha historieta, etc.), son un nuevo estrato en la historia de estos relatos. Como tal, presenta tanto rupturas como elementos comunes con las versiones anteriores. Las estrategias analizadas en este trabajo asumen el espacio fronterizo que permite reconocer la historia tradicional $\mathrm{y}$, al mismo tiempo, afirmar la novedad. Identificar y analizar estas estrategias posibilita señalar e interpretar las transformaciones en la transmisión cultural propia de nuestro tiempo.

El problema de la continuidad con la tradición es, por otra parte, una cuestión para continuar investigando. En una cultura cuyo rasgo no es la estabilidad sino la inestabilidad y la marketinización de las tradiciones, la función del folklore seguramente ya no es la misma. Rowe se pregunta si tendremos el coraje y la energía para cultivar el terreno del que surgirán los cuentos tradicionales del futuro (1986). Si por esto se refiere a folktales, entonces tal vez la respuesta sea no. La escala de la producción literaria (por no mencionar la producción digital y cinematográfica) lo hace imposible. El carácter efímero, el interés transitorio de estas producciones, también. La multiplicación y 'horizontalización' de los modelos, hacen que la tradición se debilite como tal. Esta función ha sido reemplazada por la literatura 'didáctica' (lavarse los dientes, no tener miedo a la oscuridad, etc.). Pero más importante aún, el sentido de la producción literaria, los caminos estéticos de la literatura presente, lo impide.

En todas las modalidades de citación del cuento tradicional se reconoce una actualización del contexto y cambios de paradigmas que son propios de las preocupaciones de la realidad. Sin embargo, en los textos seleccionados esta adaptación al presente no tienen por fin explícito la transmisión de valores tradicionales; y, se podría decir, tampoco tienen por fin explícito la enseñanza de valores actuales. Las actualizaciones del contexto operan más como un contraste intertextual con efectos humorísticos o incluso irónicos antes que como herramientas didácticas o ideológicas. En otras palabras, las reescrituras seleccionadas no se subordinan al objetivo de mantener la vigencia de los cuentos tradicionales, si bien pueden contribuir a cierta continuidad de la tradición. No obstante, es indudable que estos textos tienen un valor literario por sí mismos aunque su riqueza dependa en parte de que el lector conozca alguna versión del cuento tradicional en la mayoría de los ejemplos. Así, estas reescrituras son a un tiempo agentes de la transmisión cultural y productoras de cultura contemporánea; acercan a los más nuevos el mundo que les preexiste, y abre ese mundo a la novedad. 


\section{REFERENCIAS}

ALCUBIERRE MOYA, B. (2005). El cuento de hadas como código de conducta y sus adaptaciones en el contexto hispanoamericano. Boletín Del Instituto De Investigaciones Bibliográficas (UNAM), vol. x, núms. 1 y 2.

ANDRUETTO, M.T. (2021). Entrevista expuesta durante el Taller “¿Por qué son irresistibles los cuentos de hadas?, organizado por ALIJA, 7 y 14 de agosto de 2021.

ARDUINI, S. y NERGAARD, S. (2011). Translation: a new paradigm. En Translation. A transdisciplinary journal, Inaugural Issue, 8-17.

BAKER-SPERRY, L. y GRAUERHOLZ, L. (2003). The pervasiveness and persistence of the feminine beauty ideal in chldren's fairy tales. Gender \& Society, Vol 15, No 15, pp. 711-726. https://doi.org/10.1177/0891243203255605

BASSNETT, S. (2007). Culture and Translation. The Companion to Translation Studies/Edited by Piotr Kuhiwczak and Karin Littau. https://doi.org/10.21832/9781853599583-003

BASSNETT, S. y TRIVEDI, H. Eds. (2005[1999]). Post-Colonial Translation. Theory and Practice. Routledge.

CARRANZA, M. (2012). Los clásicos infantiles, esos inadaptados de siempre. Algunas cuestiones sobre la adaptación en la literatura infantil. Revista Imaginaria N 313. Recuperado de https://imaginaria.com.ar/2012/05/los-clasicos-infantiles-esosinadaptados-de-siempre-algunas-cuestiones-sobre-la-adaptacion-en-la-literaturainfantil/

CASADO PRESA, C. (2017). Y no vivieron felices para siempre: la reescritura del cuento de hadas y la problemática de la subjetividad femenina en Nueva historia de la princesa y el dragón de Carmen Resino. Feminismo/s, 30, pp. 31-46. https://doi.org/10.14198/fem.2017.30.02

CERRILLO, P. (2016). El lector literario. México, Fondo de Cultura Económica.

COLASANTI, M. (2004). Fragatas para tierras lejanas: conferencias sobre literature. Bogotá: Norma.

COLOMER, T. (1996). Eterna Caperucita. La renovación del imaginario colectivo. Cuadernos de Literatura Infantil y Juvenil 87, 7-19 http://www.fundaciongsr.org/documentos/3911.pdf.

DI PAOLA, M. (2018). Traducción visual. Epistemología de la traducción en las artes visuales. Boletín de Arte N. ${ }^{\circ} 18$, e003, 1-9. https://doi.org/10.24215/23142502e003

DURAÑONA, M. et al. (2006). Textos que dialogan: La intertextualidad como recurso didáctico. Madrid: Comunidad de Madrid.

FEIJOO, M. D. R. (1984). La aproximación crítica: el cuento popular y el cuento literario. Archivum: Revista de la Facultad de Filología, (34), 207-216.

GENETTE, G. (1989). Palimpsestos: la literatura en segundo grado. Madrid, Editorial Taurus.

HERMANS, T. (2007). Literary translation. Piotr Kuhiwczak y Karin Littau (Eds.). A companion to translation studies. G.B.: Cromwell Press Ltd, pp. 77-91. https://doi.org/10.21832/9781853599583-007

HERNÁNDEZ FERNÁNDEZ, A. (2006). Hacia una clasificación estructural y temática del cuento folclórico. En Revista de literaturas populares, año vi / número 1, 153-176.

HUTCHEON, L. (2006). A Theory of Adaptation. New York/London: Routledge. https://doi.org/10.4324/9780203957721

LOTMAN, I. (2019[1999]). La noción de frontera. La semiosfera. E-book. Lima: Saxo.com. 
MARTÍN GARZO, G. (2017). Una casa de palabras. El País, 8/01/2012, pág. 27. Recuperado de https://es.scribd.com/document/127351017/1-Gustavo-Martin-Garzo-Una-Casa-dePalabras.

MATAS GARCÍA, S. (2017). Las reescrituras de los cuentos populares en la literatura infantil y juvenil. https://addi.ehu.es/bitstream/handle/10810/20100/TFGMatasGarciaSaray.pdf ?sequence $=2$

PAC, A. et al. (2017). Cuentos de amor: tradición y ruptura en la literatura infantil. Revista Hermeneutic N15, 56-71.

PENAS-IBÁÑEZ, B. (2017). Translation and its Hybridizing Role within the Semiosphera: Fenollosa -Hearn - Pound - Noguchi. Transfer XII: 1-2, 129-160.

PROPP, V. (2009). Morfología del cuento. Madrid: Ediciones Akal.

RODRÍGUEZ ALMODOVAR, A. (1989). Los cuentos populares o la tentativa de un texto infinito. Recuperado de http://www.cervantesvirtual.com/obra-visor/los-cuentospopulares-o-la-tentativa-de-un-texto-infinito-0/html/013093d4-82b2-11df-acc7002185ce6064_18.html

ROWE, K. (1986). Feminism and Fairy Tales. Zipes, J. Don't Bet on the Prince: Contemporary Feminist Fairy Tales in North America and England, pp.209-266, Aldershot: Gower.

SALMERON VÍLCHEZ, Purificación (2005) Transmisión de valores a través de los cuentos clásicos infantiles. Granada, Universidad de Granada.

SEMENENKO, A. (2012). The Texture of Culture. An Introduction to Yuri Lotman's Semiotic Theory. Palgrave Macmillan. https://doi.org/10.1057/9781137008541

SHUPING, R. (2013). Translation as Rewriting. Vol. 3 No. 18, 55-59.

SOTOMAYOR SÁEZ, M. (2005). Literatura, sociedad, educación: Las adaptaciones literarias. Revista de Educación, núm. extraordinario, pp. 217-238.

WILKIE, Ch. (2002). Relating Texts: Intertextuality. Hunt, P. (Ed.) Understanding Children's Literature. Routlege, 129-137.

ZAVALA L. (1999). Elementos para el análisis de la intertextualidad. Cuadernos de Literatura. Vol. $5 \mathrm{~N}^{\circ} 10$, pp. 26-52.

ZECCHETO, V. (2011). El persistente impulso a resemantizar. UPS-Ecuador, No. 14, pp. 127-142. https://doi.org/10.17163/uni.n14.2011.05

ZIPES, J. (2014). El irresistible cuento de hadas. Historia cultural y social de un género. México/Buenos Aires: FCE. 